\title{
Assessment of Arterial Stiffness Using the Cardio-Ankle Vascular Index
}

\author{
Toru Miyoshi Hiroshi Ito \\ Department of Cardiovascular Medicine, Okayama University, Graduate School of Medicine, \\ Dentistry, and Pharmaceutical Sciences, Okayama, Japan
}

\section{Key Words}

Arterial stiffness - Atherosclerosis - Blood pressure - Cardiovascular disease - Pulse wave velocity $\cdot$ Left ventricular mass index $\cdot$ Intima-media thickness

\begin{abstract}
Background: Arterial stiffness is an independent predictor of outcomes for patients with cardiovascular disease. Although measurement of pulse wave velocity is a widely accepted, noninvasive approach for the assessment of arterial stiffness, its accuracy is affected by changes in blood pressure. Summary: The cardio-ankle vascular index (CAVI) is an index of the overall stiffness of the artery from the origin of the aorta to the ankle and is theoretically independent of blood pressure at the time of measurement. CAVI increases linearly with age and is elevated even in mild arteriosclerotic disease. It can identify differences in the degree of arteriosclerosis among patients with severe arteriosclerotic disease and better reflects the severity of disease of the coronary artery than does brachial-ankle pulse wave velocity. Patients with higher CAVI values show a poor prognosis compared with those with lower CAVI values. Furthermore, CAVI can be lowered by controlling diabetes mellitus and hypertension. Key Messages: The primary aims of assessing arterial stiffness using CAVI are to assist in the early detection of arteriosclerosis, allowing timely treatment and lifestyle modification, and to quantitatively evaluate the progression of disease and the effectiveness of treatment. Whether CAVI-guided therapy can improve prognosis in high-risk patients needs to be further examined to confirm the clinical usefulness of this measure.

(C) 2016 S. Karger AG, Basel
\end{abstract}

\section{Background}

With the aging of society and the adoption of westernized lifestyles, a substantial number of patients are developing arteriosclerosis, which can, in turn, lead to cardiovascular events. These adverse events not only affect the quality of life but may also lead to a poor outcome. 


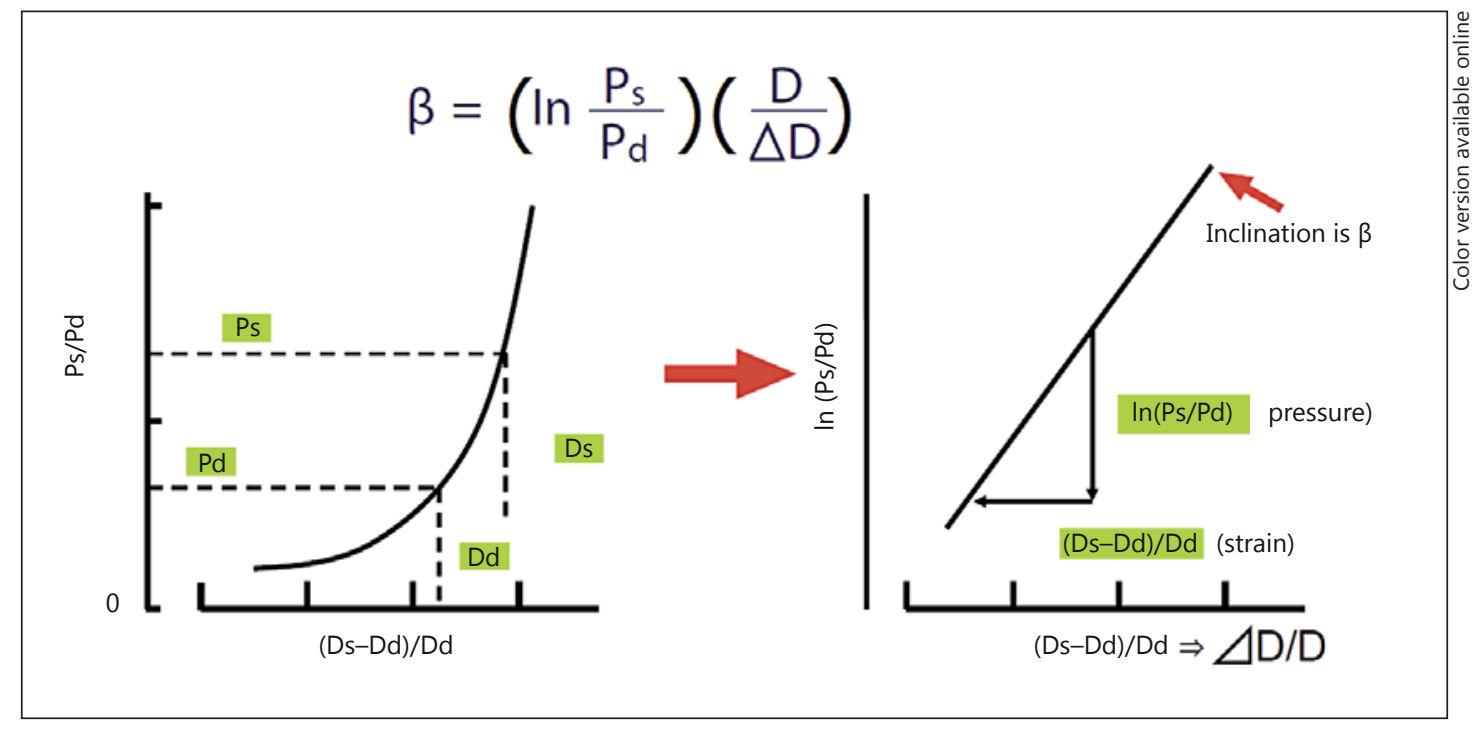

Fig. 1. Pressure-diameter curve of an artery, and definition of stiffness parameter $\beta$ [10].

Previous studies aimed at predicting cardiovascular events have focused on identifying biomarkers: a simple and noninvasive indicator for monitoring vascular lesions would be a powerful tool for lifestyle improvement. Among the biomarkers reported to date, arterial stiffness is associated with atherosclerotic risk factors and is regarded as a surrogate marker for the development of cardiovascular disease [1,2].

Pulse wave velocity (PWV) is used as a noninvasive index of arterial stiffness and is reported to predict cardiovascular events [3]. The use of carotid-femoral PWV (cfPWV) is widely accepted, but complicated techniques are required to obtain an accurate pulse wave [4]. cfPWV is also affected by blood pressure, an important confounding factor for cardiovascular disease [5]. Heart-femoral PWV (hfPWV) is an alternative measure of arterial stiffness, and the index is adjusted for blood pressure $[6,7]$. This method is based on the correction of blood pressure, using a fixed diastolic pressure of $80 \mathrm{~mm}$ Hg to reduce the influence of blood pressure $[6,7]$. hfPWV is expressed by the following equation:

$$
h f P W V=(L \times 1.3) /(t+t c),
$$

where $\mathrm{L}$ is the distance between the right edge of the sternum at the second intercostal space and the site of femoral pulsation, $t$ is the time interval between the rise of the carotid pulse wave and the rise of the femoral pulse wave, tc is the time interval between the second heart sound (S2) and the notch of the carotid pulse wave, and the constant 1.3 is the anatomical correction value given by Nye [5]. The clinical significance of hfPWV has been confirmed [8, 9], but its measurement requires a high level of proficiency to obtain accurate results.

Another measure of arterial stiffness, the stiffness parameter $\beta$, can be described by the following equation:

Stiffness parameter $\beta=\ln \left(P_{S} / P d\right) \times D / \Delta D$,

where Ps is the maximum (systolic) blood pressure, Pd is the minimum (diastolic) blood pressure, $\mathrm{D}$ is the diameter of the artery, and $\Delta \mathrm{D}$ is the change in arterial diameter caused by the difference in blood pressure [10] (fig. 1). Because this stiffness parameter $\beta$ represents the logarithmic change in blood pressure required to increase the arterial diameter, it is relatively independent of blood pressure. However, this stiffness parameter is difficult to evaluate in practice, 


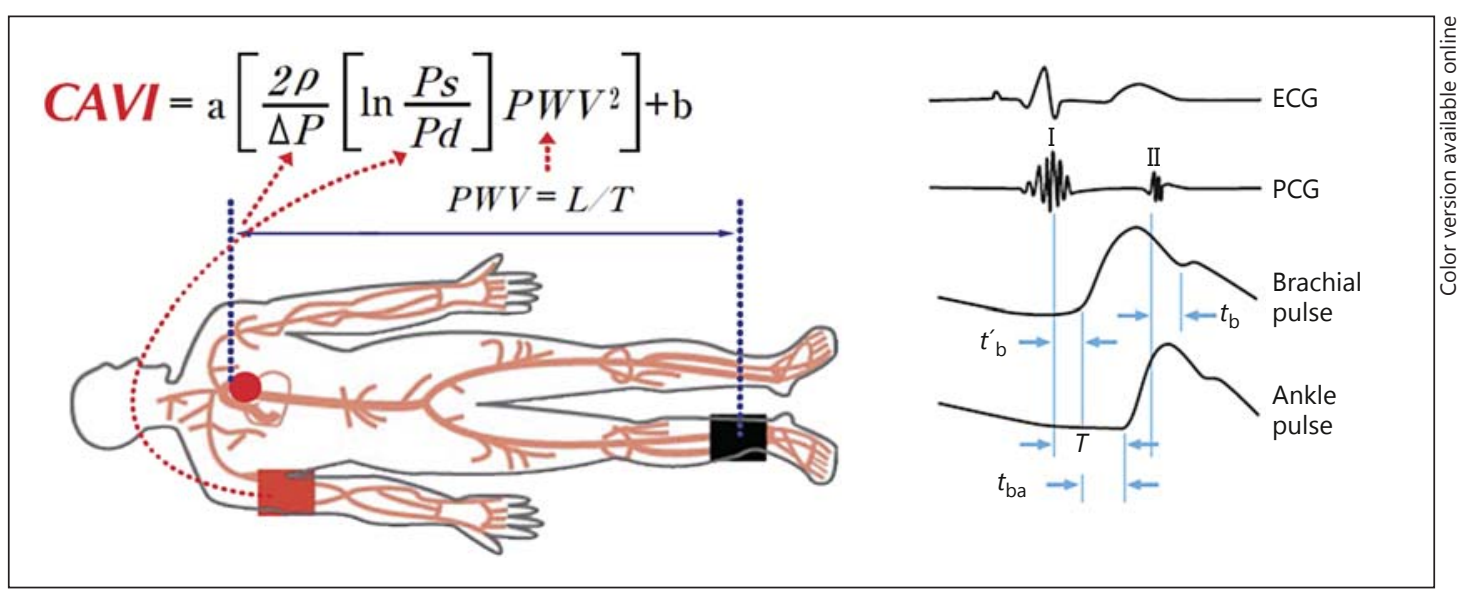

Fig. 2. Principle of CAVI measurement [11]. PWV from the heart to the ankle is obtained by measuring the length from the origin of the aorta to the ankle and by calculating $T=t_{\mathrm{b}}+t_{\mathrm{ba}}$. Blood pressure is measured at the brachial artery. $\mathrm{T}=$ Time taken from the pulse pressure wave to propagate from the aortic valve to the ankle; $t_{b a}=$ time between the rise of brachial pulse wave and the rise of the ankle pulse wave; $t_{b}=$ time between the aortic valve closing sound and the notch of the brachial pulse wave; $t_{b}{ }_{b}=$ time between the aortic valve opening sound and the rise of the brachial pulse wave.

because it is obtained by assessing only a local segment of the artery and it needs simultaneous, high-fidelity assessment of both pressure and diameter changes in a given artery [10].

In 2004, a new arterial stiffness index, the cardio-ankle vascular index (CAVI), was developed by combining two indices [11]: the stiffness parameter $\beta$ [12] and the BramwellHill formula [13]. CAVI is capable of quantitatively evaluating vascular wall stiffness in the aorta, femoral arteries, and tibial artery by measuring hfPWV and blood pressure [11]. It has been shown to have a weaker correlation with systolic blood pressure and better reproducibility than brachial-ankle PWV (baPWV) $[11,14,15]$. It has also been reported that CAVI correlates with other cardiovascular risk markers, such as intimal-medial thickening and coronary atherosclerosis [16].

\section{Technical Aspects}

\section{The Principle of CAVI}

CAVI is calculated using the heart-ankle PWV from the origin of the aortic valve to the ankle region and blood pressure measured at the upper arm (fig. 2). The Bramwell-Hill formula is used, which represents the relationship between PWV and change in volume [13], and is derived from the stiffness parameter $\beta$ first proposed by Hayashi et al. [10]. CAVI is calculated as follows:

$$
C A V I=\mathrm{a}\left[(2 \rho / \Delta P) \times \ln (P s / P d) \times P W V^{2}\right]+\mathrm{b},
$$

(equation 1)

where Ps is systolic blood pressure, Pd is diastolic blood pressure, PWV is the pulse wave velocity from the aortic origin to the ankle region via the femoral artery, $\Delta \mathrm{P}$ is $\mathrm{Ps}-\mathrm{Pd}, \rho$ is blood density of $1.05 \mathrm{~g} / \mathrm{ml}$, and a and $\mathrm{b}$ are constants for converting a CAVI value into a value obtained by Hasegawa's method [6, 7]. The formula for the stiffness parameter $\beta$ includes D/ $\Delta \mathrm{D}$, which can be obtained by modifying the Bramwell-Hill formula [13]:

$P W V^{2}=\Delta P / \rho \times V / \Delta V$, 
where $\Delta \mathrm{P}$ is pulse pressure, $\mathrm{V}$ is blood vessel volume, $\Delta \mathrm{V}$ is the change in $\mathrm{V}$, and $\rho$ is blood density. $V / \Delta V$ can be expressed by $\mathrm{D}$ and $\Delta \mathrm{D}$, as shown below:

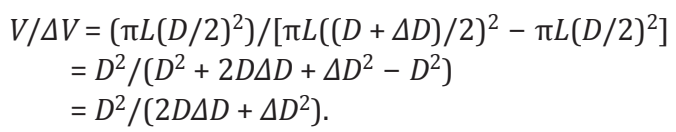

Because $\Delta \mathrm{D}^{2}$ is negligible compared with $2 \mathrm{D} \Delta \mathrm{D}$, the equation thus becomes

$V / \Delta V \sim D^{2} / 2 D \times \Delta D=D / 2 \Delta D$.

(equation 3)

Therefore, $\mathrm{V} / \Delta \mathrm{V}$ in equation 2 can be replaced by $\mathrm{D} / 2 \Delta \mathrm{D}$. Equation 2 becomes

$$
P W V^{2}=\Delta P / \rho \times V / \Delta V=\Delta P / \rho \times D / 2 \Delta D,
$$

which can be rearranged as follows:

$$
D / \Delta D=2 \rho / \Delta P \times P W V^{2} .
$$

(equation 4)

Therefore, the new $\beta$ value can be obtained by substituting equation 4 in the stiffness parameter $\beta$ equation, as shown below:

$$
\begin{aligned}
& \beta=\ln (P s / P d) \times(D / \Delta D) \\
& =\ln (P s / P d) \times 2 \rho / \Delta P \times P W V^{2} .
\end{aligned}
$$

(equation 1)

The new equation for the stiffness parameter $\beta$ obtained in this manner reflects the overall stiffness of the aorta, femoral arteries, and tibial artery. Therefore, the equation is named the 'CAVI'. Theoretically, CAVI is independent of blood pressure and essentially reflects the stiffness parameter $\beta$ based on this principle.

\section{Devices for Measuring CAVI}

CAVI is calculated automatically using the VaSera VS-Series Vascular Screening System (Fukuda Denshi, Tokyo, Japan). Measurement of CAVI requires placement of ECG electrodes on both wrists and a microphone for phonocardiography on the sternum in the second intercostal space, and four blood pressure cuffs are wrapped around the four extremities. In this manner, the upper arm and ankle pulse waves, as well as blood pressure, can all be measured using plethysmography. This obviates some of the problems related to the sites for measurement (i.e., femoral attachment in cfPWV and local evaluation of the stiffness parameter $\beta$ ) and provides overall arterial stiffness from the heart to the ankle. This method also simultaneously measures the ankle-brachial index, another physiological measure of vascular health. Devices for measuring CAVI are compact and portable, and their operation is relatively simple. Measurement of CAVI only takes less than $10 \mathrm{~min}$ at the resting state for one test. The CAVI measurement device is widely used in the clinical setting (more than 15,000 units placed in hospitals, clinics/GPs, and health centers) especially in Japan because of its ease of use and reproducibility, as it is less dependent on blood pressure. It was reported that 1,350 units were distributed in 2014 in Japan (distribution of 600 units of the baPWV measurement device in the same year was reported; https://www.yanoresearch.com/market_reports/ C57111000).

\section{Measurement Method of CAVI and Reproducibility}

The precision of pulse wave measurement is important. In particular, determination of the point representing the foot of the pulse wave is crucial for diagnostic accuracy. The VaSera device uses the amplitude adaptive tangent method to detect the foot of the pulse wave. Yambe et al. [17] compared the accuracies of eight different methods, including the amplitude adaptive tangent method. They examined 1,902 patients in clinical practice and 21 consec- 
Fig. 3. Relationship between CAVI and aortic stiffness parame$\operatorname{ter} \beta[\operatorname{Ao}(\beta)][22]$.

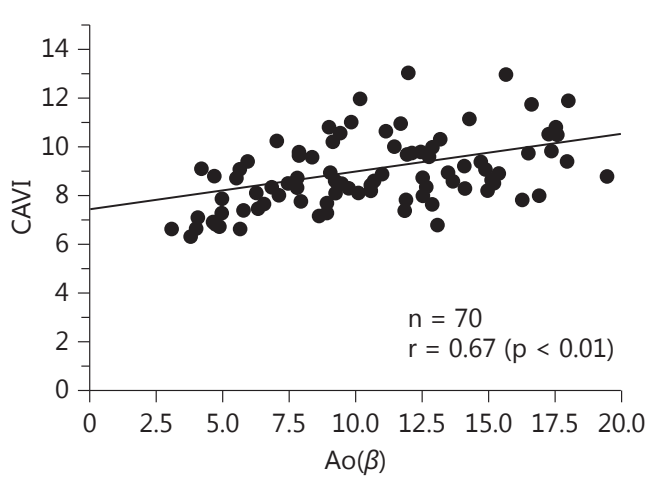

utive patients who were measured by experienced technicians, and the data were analyzed for comparison of standard deviations. They found a relatively small variability for the amplitude adaptive tangent method. Moreover, among the 4 patients who had large variability, the amplitude adaptive tangent method generated the smallest standard deviation for 3 of them.

PWV from the heart to the ankle is obtained by measuring the length from the aorta to the ankle and the time taken for the pulse wave to propagate from the aortic valve to the ankle. Vascular length $\mathrm{L}$ between the heart valve and ankle artery is indirectly calculated from the individual height of the patient using the following formula:

$$
L=0.77685 \times \text { height }-1.7536(\mathrm{~cm})
$$

Suzuki and Ishizuka [18] reported that CAVI obtained by height conversion has sufficient accuracy. The estimated vessel length significantly correlated $(r=0.877)$ with the actually measured vessel length. Moreover, CAVI determined using the vessel length obtained by the abovementioned height conversion correlated with CAVI determined using the actually measured vessel length $(\mathrm{r}=0.984)$.

The coefficients of variation of CAVI are relatively small. With regard to the repeatability of measurements, Li et al. [19] reported a 3.2\% difference between two measurements in a study of 70 people. With regard to intraobserver reproducibility at different times, Shirai et al. [11] reported a variability of 3.8\% in a study of 22 patients, Kumagai et al. [20] reported a variability of $2.8 \%$ in a study of 25 patients, Li et al. [19] reported a variability of $2.9 \%$ in a study of 7 patients, and Lim et al. [21] reported a variability of 3.4\% in a study of 50 patients. With regard to interobserver reproducibility with different operators, Lim et al. [21] reported a variability of $2.4 \%$ in a study of 50 patients. Kubozono et al. [14] also reported good reproducibility of CAVI measurements as determined by Bland-Altman plot analysis. In clinical practice, for some patients, performing highly accurate measurements or diagnoses is not always feasible in an ideal environment. Therefore, consistent measurement results can be obtained using CAVI.

\section{Comparison of CAVI with Aortic Stiffness}

Takaki et al. [22] studied the relationship between CAVI and the stiffness parameter $\beta$. They showed that CAVI was correlated with the stiffness parameter $\beta$ in the descending thoracic aorta $(r=0.67, p<0.01)$ by transesophageal echocardiography (fig. 3$)$. Horinaka et al. [23] reported that CAVI was correlated with the stiffness parameter $\beta$ in the ascending and descending thoracic aortas as calculated from ECG-gated multidetector row computed tomog- 


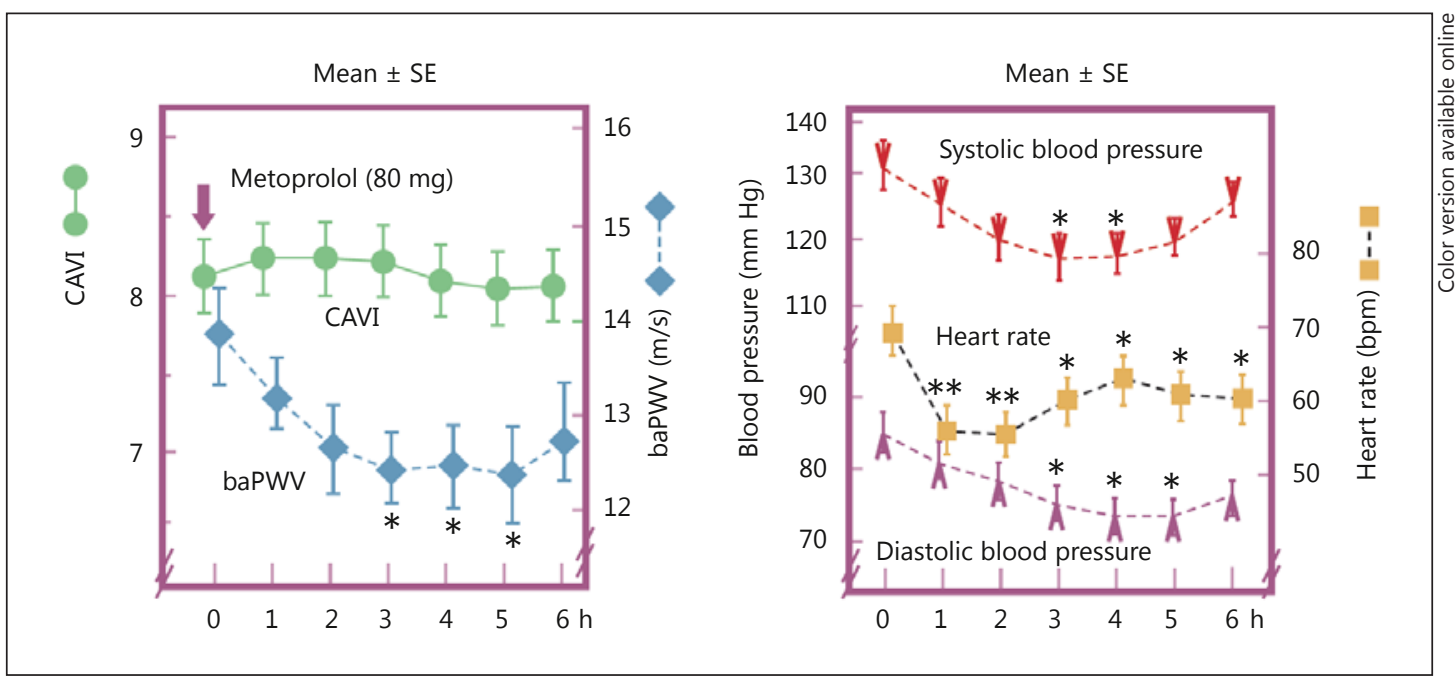

Fig. 4. Effect of metoprolol on CAVI, baPWV, blood pressure, and heart rate [26]. * $\mathrm{p}<0.05,{ }^{* *} \mathrm{p}<0.01$ vs. baseline value.

raphy. Recently, Schillaci et al. [24] reported a significant association between CAVI and cfPWV, and that CAVI may have a relationship to left ventricular structure and function that is independent of blood pressure levels. These findings support the potential role for CAVI as part of an integrated approach for evaluating central arterial stiffness in the aorta, even if it is a different physiological parameter from cfPWV.

\section{Effect of Blood Pressure on CAVI Measurement}

Several clinical and experimental studies have shown that CAVI is independent of blood pressure at the time of measurement, unlike PWV $[11,14,16,22,25,26]$. In terms of effects of blood pressure, acute and chronic effects of high blood pressure on arterial stiffness should be considered differently. Lim et al. [21] reported the impact of blood pressure perturbations on arterial stiffness using physiological and psychological interventions, and both the stiffness parameter $\beta$ and CAVI were somewhat dependent on blood pressure changes. An interpretation of this result should be cautious, because of the difficulty of eliminating the autonomic nerve effect. An experimental comparative study examined the acute effect of several blood pressure-modifying drugs, such as the $\beta_{1}$-adrenoceptor blocker metoprolol [26]. CAVI and baPWV were measured every hour for $6 \mathrm{~h}$ after administering the drugs. In the metoprolol group, mean systolic blood pressure decreased from 131.4 to $118.3 \mathrm{~mm} \mathrm{Hg}(\mathrm{p}<0.05)$ and mean diastolic blood pressure decreased from 85.3 to $75.3 \mathrm{~mm} \mathrm{Hg} \mathrm{(p<0.05).} \mathrm{baPWV} \mathrm{also}$ decreased from 13.9 to $12.5 \mathrm{~m} / \mathrm{s}(\mathrm{p}<0.05)$ after drug treatment, whereas CAVI did not change (from 8.2 to $8.2, p=0.45$ ). Similar results showing CAVI independent of blood pressure were also found after treatment with the $\alpha_{1}$-adrenoceptor blocker doxazosin (fig. 4).

\section{Reference Values for CAVI by Age and Sex}

To determine the reference values for CAVI, a large-scale study was conducted in Japan in healthy individuals free of cardiovascular disease [27]. In men, CAVI linearly increased with age, from 20 to 70 years. CAVI in men was higher than that in women for almost all age groups, but men and women showed a similar rate of increase in CAVI of approximately 0.5 per year (fig. 5). As CAVI is derived from hfPWV, the clinical threshold of 9.0 is used based on the evidence using hfPWV. The implications of CAVI for predicting cardiovascular disease are discussed below. 
Fig. 5. CAVI in healthy Japanese people at different ages. CAVI was measured in Japanese workers and their families. CAVI increased with age, and the values of CAVI were higher in men than in women at any age. CAVI $=0.5$ by 10 years; men > women by 0.2 (= difference of 5 years) [27].

Fig. 6. Box and whisker plots showing CAVI in OVD, 1VD, 2VD, and 3VD [28]. 0VD = No significant stenosis; $1 \mathrm{VD}$ = single-vessel disease; $2 \mathrm{VD}$ = double-vessel disease; $3 \mathrm{VD}=$ triple-vessel disease.
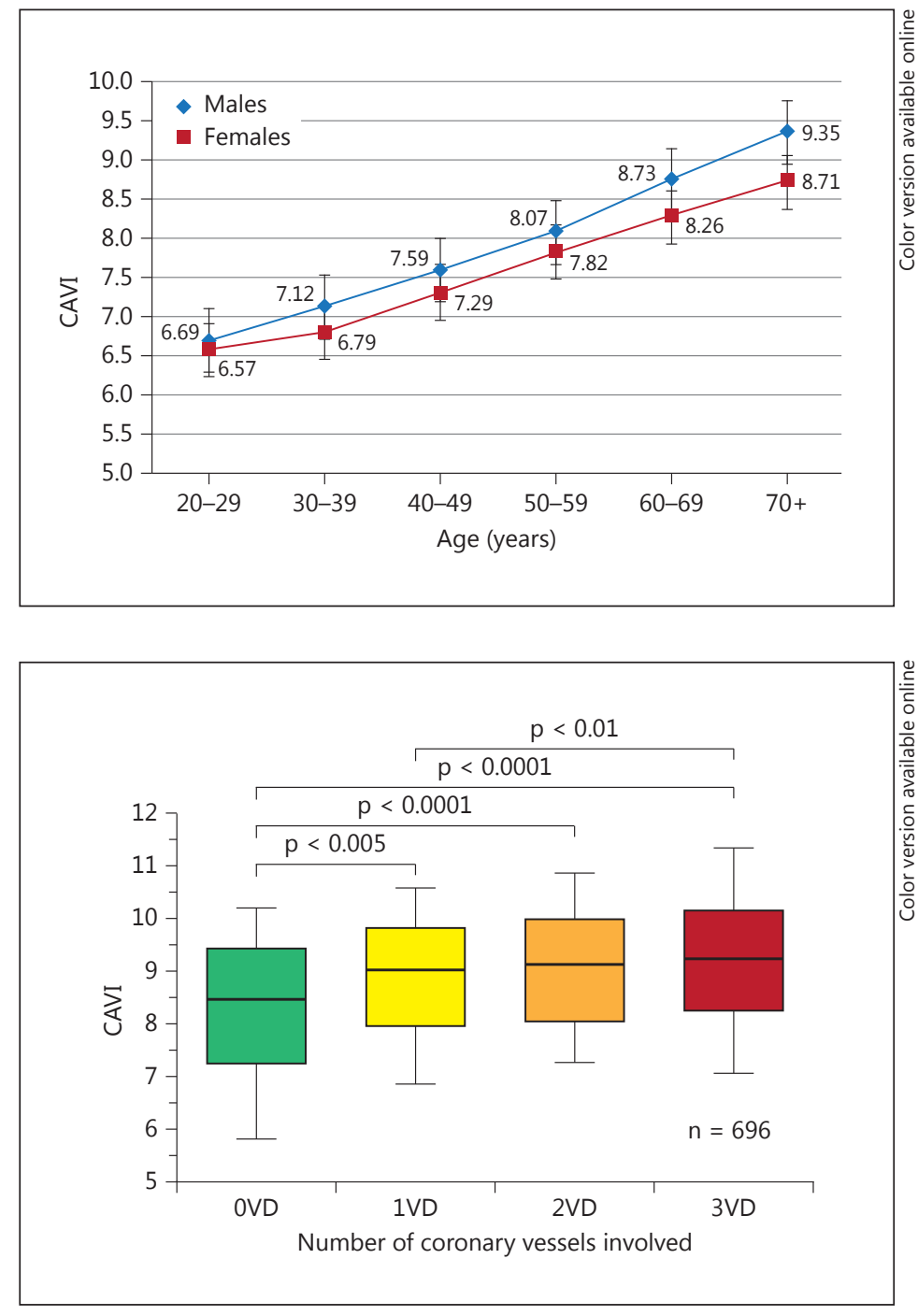

\section{Clinical Applications of CAVI}

The utility of CAVI in clinical medicine is currently under investigation by many researchers worldwide. The number of published papers on CAVI is increasing yearly and reached more than 300 in September 2015; more than 100 articles were written by nonJapanese investigators. Horinaka et al. [28] reported that CAVI increases as the number of coronary vessels with stenosis ( $>75 \%$ ) increases (fig. 6). Moreover, using receiver operating characteristic curves, they reported that the diagnostic accuracy of CAVI for coronary artery disease was significantly higher than that of baPWV. They concluded that CAVI showed better performance than baPWV in predicting coronary artery disease. The cutoff point for CAVI for the presence of coronary stenosis was 8.81 in patients with suspected ischemic coronary artery disease [29]. Yingchoncharoen et al. [30] reported that the incremental C-statistic value of CAVI was 0.13 for predicting coronary artery disease compared with the traditional risk score. Several studies have shown a relationship between CAVI and carotid arteriosclerosis as observed with ultrasonography. Izuhara et al. [31] reported that CAVI is strongly correlated with intima-media thickness, with a much stronger correlation with plaque score. 
The combination of CAVI and intima-media thickness might be a significant predictor of cerebral thrombosis in patients with severe atherosclerosis.

CAVI is high in patients with cerebral infarction. Suzuki et al. [32] found that the average CAVI in patients with transient ischemic attack, white matter ischemic lesions, large artery atherosclerosis, and small vessel occlusion was $9.3 \pm 1.5,10.3 \pm 1.3,10.2 \pm 1.2$, and $10.0 \pm 1.6$, respectively. Choi et al. [33] reported that CAVI reflects cerebral small vessel diseases in healthy young and middle-aged individuals.

High elasticity of the arterial wall reduces the load of the left ventricle. Miyoshi et al. [34] demonstrated that CAVI is associated with left ventricular diastolic function. Schillaci et al. [24] reported an association between CAVI and left ventricular mass. Zhang et al. [35] measured CAVI during therapy of congestive heart failure patients. They found that CAVI was decreased during therapy, and improvement of heart function, such as ejection fraction, was strongly correlated with CAVI. These results indicate that there is a relationship between left ventricular function and vascular function as indicated by CAVI. In addition, CAVI was reported to be increased in patients with paroxysmal atrial fibrillation compared with the control population [36]. This finding suggests that an increase in arterial stiffness leads to left ventricular hypertrophy and elevated filling pressure and results in left atrial remodeling.

The renin-angiotensin-aldosterone system is an important regulator of blood pressure. There are several studies on the effects of angiotensin II receptor antagonists on CAVI. Telmisartan decreases CAVI [37], and candesartan reduces CAVI more than telmisartan and losartan [38]. Bokuda et al. [39] studied the effects of candesartan compared with calcium channel blockers (CCBs). They showed that blood pressure was significantly decreased in both groups at the same rates. However, candesartan, but not CCBs, significantly reduced CAVI. Miyashita et al. [40] also reported that olmesartan, but not amlodipine, significantly decreased CAVI, even though the decrease in blood pressure was similar between the drugs. For treatment of hypertension, angiotensin II receptor antagonists or angiotensin-converting enzyme inhibitors have better effects on the outcomes of cardiovascular disease than do CCBs [41]. Interestingly, angiotensin II receptor antagonists are superior to CCBs in long-term prospective studies compared with short-term studies using CAVI.

In addition to the cholesterol-lowering effects of statins, they have the effect of reducing oxidative stress, which has also been examined using CAVI [42]. A single-arm intervention study investigated the effect of pitavastatin ( $2 \mathrm{mg} /$ day) for 12 months on CAVI in patients with type 2 diabetes mellitus $\left[\mathrm{n}=45(\mathrm{men} /\right.$ women $=19 / 26)$, mean age $=66$ years, $\mathrm{HbA}_{1 \mathrm{c}}=$ $6.9 \%$ ] [42]. After pitavastatin treatment, significant decreases in mean levels of serum lowdensity lipoprotein cholesterol (LDL-C; from 166 to $127 \mathrm{mg} / \mathrm{dl}, \mathrm{p}<0.01$ ), MDA-LDL, a marker of oxidatively modified LDL (from 170 to $114 \mathrm{U} / \mathrm{l}, \mathrm{p}<0.01$ ), and CAVI (from 9.54 to 8.91, $\mathrm{p}<$ $0.05)$ were observed. Further correlation analysis showed that the change in CAVI was significantly and positively correlated with that of MDA-LDL $(r=0.55, \mathrm{p}<0.05)$, but not with that of LDL-C, during pre- and posttreatment periods.

With regard to the prognostic value of CAVI, a few studies have reported its relationship to future cardiovascular events. Kubota et al. [43] reported that a group with CAVI over 10 showed a high incidence of heart disease and cerebrovascular accidents within 3 years (fig. 7). Otsuka et al. [44] investigated the association between changes in CAVI following an intervention and the incidence of long-term cardiovascular events. They set the normal CAVI based on the CAVI of healthy adults and registered 211 coronary artery disease patients with impaired CAVI. CAVI was improved in 106 patients (50\%) but not in 105 patients (50\%). The incidence of long-term cardiovascular events was significantly higher in the unimproved group than in the improved group [44]. Satoh-Asahara et al. [45] studied 425 obese patients over a 5-year follow-up. In an analysis of models adjusted for traditional risk factors, CAVI 
Fig. 7. Cumulative incidence of coronary artery disease and stroke in different CAVI groups [43].

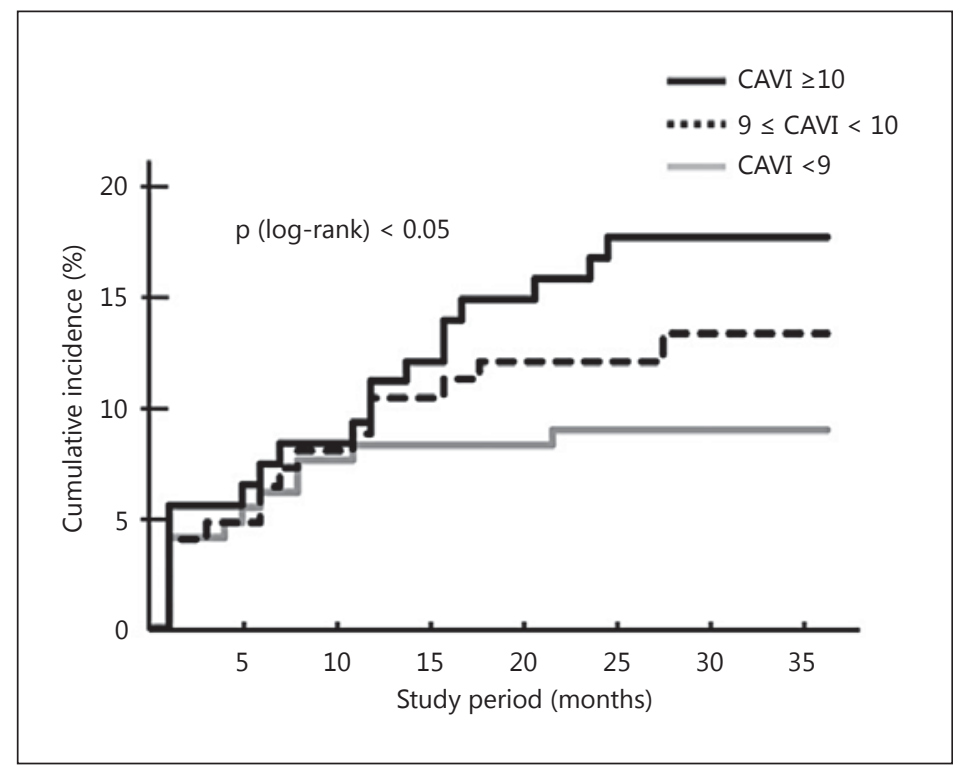

was a significant risk factor for the incidence of events. CAVI added value to the atherosclerotic cardiovascular disease risk score in predicting the development of cardiovascular disease [45]. Laucevičius et al. [46] investigated the association of CAVI with cardiovascular risk factors and events in 2,106 middle-aged metabolic syndrome patients without overt atherosclerotic disease. In the 3.8 years of follow-up, CAVI was significantly associated with occurrence of total cardiovascular events ( $p=0.045$ ). In Japan, the CAVI-J study ('Prospective study of the cardio-ankle vascular index as a predictive factor for cardiovascular events') was launched to conduct a multicenter, 5-year, prospective study of CAVI. This study aims to examine the additional benefits from using CAVI as a predictive indicator of cardiovascular events in 3,000 high-risk patients (ClinicalTrials.gov identifier: NCT01859897). The CAVI-J study is expected to determine whether CAVI has additional value over the risk score. This study also aims to determine whether the 'Framingham-CAVI score', which is a combination of the Framingham risk score and CAVI, is superior to conventional risk scores. We expect that the clinical usefulness of CAVI measurements in general practice will be established by these prospective studies.

\section{Prospective View}

In recent years, CAVI has been studied by many researchers around the world and is highly anticipated to play a role as a predictive factor for arteriosclerotic diseases [16, 32]. Such studies have shown that CAVI increases in the presence of cerebrovascular disease, dementia, cardiovascular disease, nephrosclerosis, and vasculitis. It also increases with hypertension, hyperlipidemia, and lifestyle-related diseases including diabetes mellitus, smoking, sleep apnea syndrome, stress, and obesity, which are considered risk factors for arteriosclerosis [20, 25, 28, 29, 32, 34, 40, 42, 47-55]. The American Heart Association published a scientific statement of 'Recommendations for improving and standardizing vascular research on arterial stiffness'. CAVI received a rating of 'Class I, Level of Evidence B', even though longitudinal studies in the USA and Europe are lacking. The American Heart Association also mentioned that the reproducibility of VaSera, as determined by Bland- 
Table 1. Comparison of each arterial stiffness measurement method

\begin{tabular}{|c|c|c|c|c|c|}
\hline & cfPWV & baPWV & heart-ankle PWV & CAVI & $\begin{array}{l}\text { Stiffness } \\
\text { parameter } \beta\end{array}$ \\
\hline $\begin{array}{l}\text { Physical } \\
\text { variable } \\
\text { (blood } \\
\text { pressure } \\
\text { influence) }\end{array}$ & $\begin{array}{l}\text { PWV } \\
\text { (dependent) }\end{array}$ & $\begin{array}{l}\text { PWV } \\
\text { (dependent) }\end{array}$ & $\begin{array}{l}\text { PWV } \\
\text { (dependent) }\end{array}$ & $\begin{array}{l}\text { Stiffness } \\
\text { (less dependent) }\end{array}$ & $\begin{array}{l}\text { Stiffness } \\
\text { (less } \\
\text { dependent) }\end{array}$ \\
\hline Sensor & $\begin{array}{l}\text { Applanation } \\
\text { tonometry }\end{array}$ & $\begin{array}{l}\text { Plethysmography } \\
\text { cuff }\end{array}$ & $\begin{array}{l}\text { Plethysmography } \\
\text { cuff }\end{array}$ & $\begin{array}{l}\text { Plethysmography } \\
\text { cuff }\end{array}$ & Ultrasound \\
\hline $\begin{array}{l}\text { Measured } \\
\text { arteries }\end{array}$ & Segment & Segment & Segment & Segment & Local \\
\hline Carotid & 0 & & & & - \\
\hline Ascending & & & 0 & 0 & \\
\hline Descending & 0 & 0 & 0 & 0 & \\
\hline Abdominal & 0 & 0 & 0 & 0 & - \\
\hline Femoral & 0 & 0 & 0 & 0 & - \\
\hline Ankle & & $\bigcirc$ & O & O & \\
\hline Brachial & & 0 & & & \\
\hline
\end{tabular}

Altman plot analysis, is good [56]. As described in section Clinical Applications of CAVI, many longitudinal studies are ongoing around the world. These results will show evidence of the prospective value of CAVI, and meta-analysis may be performed to obtain a higher level of evidence.

CAVI is a noninvasive indicator of arterial stiffness. The main advantages of CAVI over other procedures for measuring arterial stiffness are as follows: (1) blood pressure independence of arterial elasticity; (2) inclusion of the ascending aorta in the area of measurement, and (3) relative simplicity and low cost. With regard to the first advantage, we can assess each patient's arterial properties by dividing into blood pressure and arterial stiffness. This enables detailed monitoring of arterial stiffness $(\triangle \mathrm{CAVI})$ and blood pressure $(\triangle \mathrm{BP})$ in each patient in daily practice. The second advantage means this measure of arterial function may have a closer relationship to cardiac function. The relationship between left ventricular function and CAVI suggests that CAVI is an adequate marker of vascular function as a Windkessel. With regard to the third advantage of the usability of CAVI in clinical situations, 15,000 units of the VaSera device, which measures CAVI, have already been installed worldwide, mainly in Asia. However, we need to further examine whether CAVI-guided therapy can improve outcomes in high-risk patients to confirm the clinical usefulness of this measure.

Table 1 shows a comparison of each arterial measurement method. For measuring aortic stiffness, $\mathrm{PWV}$, the time taken for the pressure pulse to travel between two points, is used as the current gold standard. However, PWV is not a direct measure of stiffness but a measure of the speed of the pressure pulse, which is related to stiffness and is influenced by pressure. As an alternative, CAVI was developed as a more direct measure of stiffness, and it provides a 'pressure-independent' assessment of arterial stiffness at the time of measurement and of the effect of treatment. Studies are currently underway to evaluate the clinical utility of CAVI.

In conclusion, CAVI reflects arterial stiffness from the origin of the aorta to the tibial artery at the ankle. CAVI is based on the theory of the stiffness parameter $\beta$ and provides a detailed assessment that is divided into arterial stiffness and blood pressure. Other arterial stiffness markers, such as PWV and the stiffness parameter $\beta$ itself, are also effective in the 
clinical situation. Each method for determining arterial stiffness should be used with an understanding of the theory underlying each method, features, and positioning to achieve better patient care and prevent cardiovascular events.

\section{Disclosure Statement}

The authors have no conflicts of interest to disclose.

\section{References}

1 Oliver JJ, Webb DJ: Noninvasive assessment of arterial stiffness and risk of atherosclerotic events. Arterioscler Thromb Vasc Biol 2003;23:554-566.

2 Mattace-Raso FUS, van der Cammen TJM, Hofman A, van Popele NM, Bos ML, Schalekamp MADH, Asmar R, Reneman RS, Hoeks APG, Breteler MMB, Witteman JCM: Arterial stiffness and risk of coronary heart disease and stroke: the Rotterdam Study. Circulation 2006;113:657-663.

3 Asmar R, Benetos A, Topouchian J, Laurent P, Pannier B, Brisac AM, Target R, Levy BI: Assessment of arterial distensibility by automatic pulse wave velocity measurement. Validation and clinical application studies. Hypertension 1995;26:485-490.

4 Laurent S, Boutouyrie P, Asmar R, Gautier I, Laloux B, Guize L, Ducimetiere P, Benetos A: Aortic stiffness is an independent predictor of all-cause and cardiovascular mortality in hypertensive patients. Hypertension 2001; 37:1236-1241.

5 Nye ER: The effect of blood pressure alteration on the pulse wave velocity. Br Heart J 1964;26:261-265.

6 Hasegawa M: Fundamental research on human aortic pulse wave velocity. Jikei Med J 1970;85:742-760.

7 Hasegawa M, Arai C: Clinical estimation of vascular elastic function and practical application. Connective Tissue 1995;27:149-157.

8 Hamazaki T, Urakaze M, Sawazaki S, Yamazaki K, Taki H, Yano S: Comparison of pulse wave velocity of the aorta between inhabitants of fishing and farming villages in Japan. Atherosclerosis 1988;73:157-160.

9 Saito Y, Shirai K, Uchino J, Okazawa M, Hattori Y, Yoshida T, Yoshida S: Effect of nifedipine administration on pulse wave velocity (PWV) of chronic hemodialysis patients - 2-year trial. Cardiovasc Drugs Ther 1990; 4(suppl 5):987-990.

10 Hayashi K, Handa H, Nagasawa S, Okumura A, Moritake K: Stiffness and elastic behavior of human intracranial and extracranial arteries. J Biomech 1980;13:175-184.

11 Shirai K, Utino J, Otsuka K, Takata M: A novel blood pressure-independent arterial wall stiffness parameter; cardio-ankle vascular index (CAVI). J Atheroscler Thromb 2006;13:101-107.

12 Kawasaki T, Sasayama S, Yagi S, Asakawa T, Hirai T: Non-invasive assessment of the age related changes in stiffness of major branches of the human arteries. Cardiovasc Res 1987;21:678-687.

13 Bramwell JC, Hill AV: The velocity of the pulse wave in man. Proc R Soc B Biol Sci 1922;93:298-306.

14 Kubozono T, Miyata M, Ueyama K, Nagaki A, Otsuji Y, Kusano K, Kubozono O, Tei C: Clinical significance and reproducibility of new arterial distensibility index. Circ J 2007;71:89-94.

15 Yambe M, Tomiyama H, Hirayama Y, Gulniza Z, Takata Y, Koji Y, Motobe K, Yamashina A: Arterial stiffening as a possible risk factor for both atherosclerosis and diastolic heart failure. Hypertens Res 2004;27:625-631.

16 Shirai K, Hiruta N, Song M, Kurosu T, Suzuki J, Tomaru T, Miyashita Y, Saiki A, Takahashi M, Suzuki K, Takata M: Cardio-ankle vascular index (CAVI) as a novel indicator of arterial stiffness: theory, evidence and perspectives. J Atheroscler Thromb 2011;18:924-938.

17 Yambe T, Saijo Y, Shiraishi Y, Kawata H, Konno S, Nitta S, Yamaguchi T, Nakajima H, Katahira Y, Shibata M, Watanabe M, Mibiki Y, Osawa N, Sato N, Akino Y, Honda M: Accuracy of methods for determining pulse wave foot: a clinical study. Clin Electronics 2007;76:23-34.

18 Suzuki K, Ishizuka N: Fundamental study on CAVI: blood-pressure-independent assessment of arterial stiffness. Clin Electronics 2007;76:35-45.

19 Li Y, Cordes M, Recio-Rodriguez JI, García-Ortiz L, Hanssen H, Schmidt-Trucksäss A: Diurnal variation of arterial stiffness in healthy individuals of different ages and patients with heart disease. Scand J Clin Lab Invest 2014;74:155-162.

20 Kumagai T, Kasai T, Kato M, Naito R, Maeno K, Kasagi S, Kawana F, Ishiwata S, Narui K: Establishment of the cardio-ankle vascular index in patients with obstructive sleep apnea. Chest 2009;136:779-786.

21 Lim J, Pearman ME, Park W, Alkatan M, Machin DR, Tanaka H: Impact of blood pressure perturbations on arterial stiffness. Am J Physiol Regul Integr Comp Physiol 2015;309:R1540-R1545.

22 Takaki A, Ogawa H, Wakeyama T, Iwami T, Kimura M, Hadano Y, Matsuda S, Miyazaki Y, Matsuda T, Hiratsuka A, Matsuzaki M: Cardio-ankle vascular index is a new noninvasive parameter of arterial stiffness. Circ J 2007; 71:1710-1714. 
23 Horinaka S, Yagi H, Ishimura K, Fukushima H, Shibata Y, Sugawara R, Ishimitsu T: Cardio-ankle vascular index (CAVI) correlates with aortic stiffness in the thoracic aorta using ECG-gated multi-detector row computed tomography. Atherosclerosis 2014;235:239-245.

24 Schillaci G, Battista F, Settimi L, Anastasio F, Pucci G: Cardio-ankle vascular index and subclinical heart disease Hypertens Res 2015;38:68-73.

25 Ibata J, Sasaki H, Kakimoto T, Matsuno S, Nakatani M, Kobayashi M, Tatsumi K, Nakano Y, Wakasaki H, Furuta H, Nishi M, Nanjo K: Cardio-ankle vascular index measures arterial wall stiffness independent of blood pressure. Diabetes Res Clin Pract 2008;80:265-270.

26 Shirai K, Song M, Suzuki J, Kurosu T, Oyama T, Nagayama D, Miyashita Y, Yamamura S, Takahashi M: Contradictory effects of $\beta_{1}$ - and $\alpha_{1}$-aderenergic receptor blockers on cardio-ankle vascular stiffness index (CAVI) CAVI independent of blood pressure. J Atheroscler Thromb 2011;18:49-55.

27 Namekata T, Suzuki K, Ishizuka N, Shirai K: Establishing baseline criteria of cardio-ankle vascular index as a new indicator of arteriosclerosis: a cross-sectional study. BMC Cardiovasc Disord 2011;11:51.

28 Horinaka S, Yabe A, Yagi H, Ishimura K, Hara H, Iemua T, Matsuoka H: Comparison of atherosclerotic indicators between cardio ankle vascular index and brachial ankle pulse wave velocity. Angiology 2009;60:468-476.

29 Nakamura K, Tomaru T, Yamamura S, Miyashita Y, Shirai K, Noike H: Cardio-ankle vascular index is a candidate predictor of coronary atherosclerosis. Circ J 2008;72:598-604.

30 Yingchoncharoen T, Limpijankit T, Jongjirasiri S, Laothamatas J, Yamwong S, Sritara P: Arterial stiffness contributes to coronary artery disease risk prediction beyond the traditional risk score (RAMA-EGAT score). Heart Asia 2012;4:77-82.

31 Izuhara M, Shioji K, Kadota S, Baba O, Takeuchi Y, Uegaito T, Mutsuo S, Matsuda M: Relationship of cardio-ankle vascular index (CAVI) to carotid and coronary arteriosclerosis. Circ J 2008;72:1762-1767.

32 Suzuki J, Sakakibara R, Tomaru T, Tateno F, Kishi M, Ogawa E, Kurosu T, Shirai K: Stroke and cardio-ankle vascular stiffness index. J Stroke Cerebrovasc Dis 2013;22:171-175.

33 Choi SY, Park HE, Seo H, Kim M, Cho SH, Oh BH: Arterial stiffness using cardio-ankle vascular index reflects cerebral small vessel disease in healthy young and middle aged subjects. J Atheroscler Thromb 2013;20:178185.

34 Miyoshi T, Doi M, Hirohata S, Sakane K, Kamikawa S, Kitawaki T, Kaji Y, Kusano KF, Ninomiya Y, Kusachi S: Cardio-ankle vascular index is independently associated with the severity of coronary atherosclerosis and left ventricular function in patients with ischemic heart disease. J Atheroscler Thromb 2010;17:249-258.

35 Zhang C, Ohira M, Iizuka T, Mikamo H, Nakagami T, Suzuki M, et al: Cardio-ankle vascular index relates to left ventricular ejection fraction in patients with heart failure. A retrospective study. Int Heart J 2013;54:216-221.

36 Miyoshi T, Doi M, Noda Y, Ohno Y, Sakane K, Kamikawa S, Noguchi Y, Ito H: Arterial stiffness determined according to the cardio-ankle vascular index is associated with paroxysmal atrial fibrillation: a cross-sectional study. Heart Asia 2014;6:59-63.

37 Kinouchi K, Ichihara A, Sakoda M, Kurauchi-Mito A, Murohashi-Bokuda K, Itoh H: Effects of telmisartan on arterial stiffness assessed by the cardio-ankle vascular index in hypertensive patients. Kidney Blood Press Res 2010;33:304-312.

38 Uehara G, Takeda H: Relative effects of telmisartan, candesartan and losartan on alleviating arterial stiffness in patients with hypertension complicated by diabetes mellitus: an evaluation using the cardio-ankle vascular index (CAVI). J Int Med Res 2008;36:1094-1102.

39 Bokuda K, Ichihara A, Sakoda M, Mito A, Kinouchi K, Itoh H: Blood pressure-independent effect of candesartan on cardio-ankle vascular index in hypertensive patients with metabolic syndrome. Vasc Health Risk Manag 2010;6:571-578.

40 Miyashita Y, Saiki A, Endo K, Ban N, Yamaguchi T, Kawana H, Nagayama D, Ohira M, Oyama T, Shirai K: Effects of olmesartan, an angiotensin II receptor blocker, and amlodipine, a calcium channel blocker, on cardio-ankle vascular index (CAVI) in type 2 diabetic patients with hypertension. J Atheroscler Thromb 2009;16:621-626.

41 Ogihara T, Fujimoto A, Nakao K, Saruta T: ARB candesartan and CCB amlodipine in hypertensive patients: the CASE-J trial. Expert Rev Cardiovasc Ther 2008;6:1195-1201.

42 Miyashita Y, Endo K, Saiki A, Ban N, Yamaguchi T, Kawana H, Nagayama D, Ohira M, Oyama T, Shirai K: Effects of pitavastatin, a 3-hydroxy-3-methylglutaryl coenzyme A reductase inhibitor, on cardio-ankle vascular index in type 2 diabetic patients. J Atheroscler Thromb 2009;16:539-545.

43 Kubota Y, Maebuchi D, Takei M, Inui Y, Sudo Y, Ikegami Y, Fuse J, Sakamoto M, Momiyama Y: Cardio-ankle vascular index is a predictor of cardiovascular events. Artery Res 2011;5:91-96.

44 Otsuka K, Fukuda S, Shimada K, Suzuki K, Nakanishi K, Yoshiyama M, Yoshikawa J: Serial assessment of arterial stiffness by cardio-ankle vascular index for prediction of future cardiovascular events in patients with coronary artery disease. Hypertens Res 2014;37:1014-1020.

45 Satoh-Asahara N, Suganami T, Majima T, Kotani K, Kato Y, Araki R, Koyama K, Okajima T, Tanabe M, Oishi M, Himeno A, Kono S, Sugawara A, Hattori M, Ogawa Y, Shimatsu A: Urinary cystatin C as a potential risk marker for cardiovascular disease and chronic kidney disease in patients with obesity and metabolic syndrome. Clin J Am Soc Nephrol 2011;6:265-273.

46 Laucevičius A, Ryliškytė L, Balsytė J, Badarienė J, Puronaitė R, Navickas R, Solovjova S: Association of cardioankle vascular index with cardiovascular risk factors and cardiovascular events in metabolic syndrome patients. Medicina 2015;51:152-158. 
47 Yamamoto N, Yamanaka G, Ishikawa M, Takasugi E, Murakami S, Yamanaka T, Ishine M, Matsubayashi K, Hanafusa T, Otsuka K: Cardio-ankle vascular index as a predictor of cognitive impairment in communitydwelling elderly people: four-year follow-up. Dement Geriatr Cogn Disord 2009;28:153-158.

48 Nakamura K, Iizuka T, Takahashi M, Shimizu K, Mikamo H, Nakagami T, Suzuki M, Hirano K, Sugiyama Y, Tomaru T, Miyashita Y, Shirai K, Noike H: Association between cardio-ankle vascular index and serum cystatin C levels in patients with cardiovascular risk factor. J Atheroscler Thromb 2009;16:371-379.

49 Sato H, Miida T, Wada Y, Maruyama M, Murakami S, Hasegawa H, Kuroda T, Narita I, Nakano M, Gejyo F: Atherosclerosis is accelerated in patients with long-term well-controlled systemic lupus erythematosus (SLE). Clin Chim Acta 2007;385:35-42.

50 Masugata H, Senda S, Himoto T, Murao K, Dobashi H, Kitano Y, Okuyama H, Inukai M, Hosomi N, Kohno M, Nishiyama Y, Kohno T, Goda F: Detection of increased arterial stiffness in a patient with early stage of large vessel vasculitis by measuring cardio-ankle vascular index. Tohoku J Exp Med 2009;219:101-105.

51 Masugata H, Senda S, Dobashi H, Himoto T, Murao K, Okuyama H, Inukai M, Hosomi N, Kohno M, Nishiyama Y, Kohno T, Goda F: Cardio-ankle vascular index for evaluating immunosuppressive therapy in a patient with aortitis syndrome. Tohoku J Exp Med 2010;222:77-81.

52 Noike H, Nakamura K, Sugiyama Y, Iizuka T, Shimizu K, Takahashi M, Hirano K, Suzuki M, Mikamo H, Nakagami T, Shirai K: Changes in cardio-ankle vascular index in smoking cessation. J Atheroscler Thromb 2010;17:517525.

53 Kasai T, Inoue K, Kumagai T, Kato M, Kawana F, Sagara M, Ishiwata S, Ohno M, Yamaguchi T, Momomura S, Narui K: Plasma pentraxin3 and arterial stiffness in men with obstructive sleep apnea. Am J Hypertens 2011; 24:401-407.

54 Himeno A, Satoh-Asahara N, Usui T, Wada H, Tochiya M, Kono S, Yamada-Goto N, Katsuura G, Hasegawa K, Nakao K, Shimatsu A: Salivary cortisol levels are associated with outcomes of weight reduction therapy in obese Japanese patients. Metabolism 2012;61:255-261.

55 Satoh N, Shimatsu A, Kato Y, Araki R, Koyama K, Okajima T, Tanabe M, Ooishi M, Kotani K, Ogawa Y: Evaluation of the cardio-ankle vascular index, a new indicator of arterial stiffness independent of blood pressure, in obesity and metabolic syndrome. Hypertens Res 2008;31:1921-1930.

56 Townsend RR, Wilkinson IB, Schiffrin EL, Avolio AP, Chirinos JA, Cockcroft JR, Heffernan KS, Lakatta EG, McEniery CM, Mitchell GF, Najjar SS, Nichols WW, Urbina EM, Weber T: Recommendations for improving and standardizing vascular research on arterial stiffness: a scientific statement from the American Heart Association. Hypertension 2015;66:698-722. 